\title{
Magnetohydrodynamic Boundary Layer Flow of Nanofluid over an Exponentially Stretching Permeable Sheet
}

\author{
Krishnendu Bhattacharyya and G. C. Layek \\ Department of Mathematics, The University of Burdwan, Burdwan, West Bengal 713104, India \\ Correspondence should be addressed to Krishnendu Bhattacharyya; krish.math@yahoo.com
}

Received 19 October 2013; Accepted 7 December 2013; Published 8 January 2014

Academic Editor: Ali Hussain Reshak

Copyright (c) 2014 K. Bhattacharyya and G. C. Layek. This is an open access article distributed under the Creative Commons Attribution License, which permits unrestricted use, distribution, and reproduction in any medium, provided the original work is properly cited.

\begin{abstract}
A mathematical model of the steady boundary layer flow of nanofluid due to an exponentially permeable stretching sheet with external magnetic field is presented. In the model, the effects of Brownian motion and thermophoresis on heat transfer and nanoparticle volume friction are considered. Using shooting technique with fourth-order Runge-Kutta method the transformed equations are solved. The study reveals that the governing parameters, namely, the magnetic parameter, the wall mass transfer parameter, the Prandtl number, the Lewis number, Brownian motion parameter, and thermophoresis parameter, have major effects on the flow field, the heat transfer, and the nanoparticle volume fraction. The magnetic field makes enhancement in temperature and nanoparticle volume fraction, whereas the wall mass transfer through the porous sheet causes reduction of both. For the Brownian motion, the temperature increases and the nanoparticle volume fraction decreases. Heat transfer rate becomes low with increase of Lewis number. For thermophoresis effect, the thermal boundary layer thickness becomes larger.
\end{abstract}

\section{Introduction}

The term "nanofluid" was proposed by Choi [1], referring to dispersions of nanoparticles in the base fluids such as water, ethylene glycol, and propylene glycol. The thermal conductivity enhancement characteristic of nanofluid was observed by Masuda et al. [2]. Buongiorno [3] discussed the reasons behind the enhancement in heat transfer for nanofluid and he found that Brownian diffusion and thermophoresis are the main causes. Later, Nield and Kuznetsov [4] and Kuznetsov and Nield [5] investigated the natural convective boundary layer flow of a nanofluid employing Buongiorno model.

The study of boundary layer flow and heat transfer due to stretching surface has numerous applications in industry and technology, such as in polymer extrusion, drawing of copper wires, artificial fibers, paper production, hot rolling, wire drawing, glass fiber, metal extrusion and metal spinning, and continuous stretching of plastic films. Crane [6] first studied the boundary layer flow due to linearly stretching sheet. Many researchers [7-17] extended the work of Crane, whereas Magyari and Keller [18] considered the boundary layer flow and heat transfer due to an exponentially stretching sheet.
The flow and heat transfer over an exponentially stretching surface were investigated by Elbashbeshy [19] taking wall mass suction. Khan and Sanjayanand [20] presented the boundary layer flow of viscoelastic fluid and heat transfer over an exponentially stretching sheet with viscous dissipation effect and Partha et al. [21] reported a similarity solution for mixed convection flow past an exponentially stretching surface. Ishak [22] studied the magnetohydrodynamic (MHD) boundary layer flow over an exponentially shrinking sheet in presence of thermal radiation. Bhattacharyya [23] discussed the boundary layer flow and heat transfer caused due to an exponentially shrinking sheet and Bhattacharyya and Pop [24] showed the effect of external magnetic field on the flow over an exponentially shrinking sheet. Recently, Bhattacharyya and Vajravelu [25] described the stagnationpoint boundary layer flow due to exponentially shrinking sheet for Newtonian fluid and Bachok et al. [26] investigated the same problem for nanofluid.

The boundary layer flow of nanofluid past a linearly stretching sheet was first studied by Khan and Pop [27] introducing the model of Nield and Kuznetsov [4]. The boundary layer flow induced in a nanofluid due to a linearly stretching 
sheet with convective boundary condition was described by Makinde and Aziz [28]. Kandasamy et al. [29] investigated the MHD boundary layer flow of a nanofluid past a vertical stretching permeable surface with suction/injection. Mustafa et al. [30] reported the flow of a nanofluid near a stagnationpoint towards a stretching surface. Rana and Bhargava [31] illustrated the steady, laminar boundary layer flow due to the nonlinear stretching of a flat surface in a nanofluid. Later, Hady et al. [32] analysed the boundary layer flow and heat transfer characteristics of a viscous nanofluid over a nonlinearly stretching sheet in the presence of thermal radiation and variable wall temperature. Makinde et al. [33] discussed the combined effects of buoyancy force and magnetic field on stagnation-point flow and heat transfer in a nanofluid flow towards a stretching sheet. A theoretical study of unsteady boundary layer flow of a nanofluid over a permeable stretching/shrinking sheet was reported by Bachok et al. [34]. Recently, Nadeem and Lee [35] obtained analytic solutions of boundary layer flow of nanofluid over an exponentially stretching surface using homotopy analysis method (HAM).

In the present paper, the MHD boundary layer nanofluid flow dynamics due to an exponentially shrinking sheet is investigated. The obtained ordinary differential equations by similarity transformations are solved numerically using shooting technique with fourth-order Runge-Kutta method. Then computed results are plotted in graphs and discussed in detail.

\section{Mathematical Formulation}

Consider the steady boundary layer flow of nanofluid over an exponentially stretching sheet in presence of a transverse magnetic field. The governing equations of motion and the energy equation may be written in usual notation as $[27,35]$

$$
\begin{gathered}
\frac{\partial u}{\partial x}+\frac{\partial v}{\partial y}=0 \\
u \frac{\partial u}{\partial x}+v \frac{\partial u}{\partial y}=v \frac{\partial^{2} u}{\partial y^{2}}-\frac{\sigma B^{2}}{\rho_{f}} u \\
u \frac{\partial T}{\partial x}+v \frac{\partial T}{\partial y}=\alpha \frac{\partial^{2} T}{\partial y^{2}}+\frac{(\rho c)_{p}}{(\rho c)_{f}}\left[D_{B} \frac{\partial N}{\partial y} \frac{\partial T}{\partial y}+\frac{D_{T}}{T_{\infty}}\left(\frac{\partial T}{\partial y}\right)^{2}\right] \\
u \frac{\partial N}{\partial x}+v \frac{\partial N}{\partial y}=D_{B} \frac{\partial^{2} N}{\partial y^{2}}+\frac{D_{T}}{T_{\infty}} \frac{\partial^{2} T}{\partial y^{2}},
\end{gathered}
$$

where $u$ and $v$ are the velocity components in $x$ - and $y$ directions, respectively, $v$ is the kinematic viscosity, $\rho_{f}$ is the density of the base fluid, $T$ is the temperature, $T_{\infty}$ is constant temperature of the fluid in the inviscid free stream, $\alpha$ is the thermal conductivity, $(\rho c)_{p}$ is the effective heat capacity of nanoparticles, $(\rho c)_{f}$ is heat capacity of the base fluid, $N$ is nanoparticle volume fraction, $D_{B}$ is the Brownian diffusion coefficient, and $D_{T}$ is the thermophoretic diffusion coefficient. Here, the variable magnetic field $B(x)$ is taken in the form $[22,24]$

$$
B(x)=B_{0} \exp \left(\frac{x}{2 L}\right)
$$

where $B_{0}$ is a constant.

The boundary conditions are given by

$$
\begin{gathered}
u=U_{w}(x), \quad v=v_{w} \quad \text { at } y=0, \\
u \longrightarrow 0 \quad \text { as } y \longrightarrow \infty, \\
T=T_{w}=T_{\infty}+T_{0} \exp \left(\frac{x}{2 L}\right) \quad \text { at } y=0, \\
T \longrightarrow T_{\infty} \quad \text { as } y \longrightarrow \infty, \\
N=N_{w}=N_{\infty}+N_{0} \exp \left(\frac{x}{2 L}\right) \text { at } y=0, \\
N \longrightarrow N_{\infty} \quad \text { as } y \longrightarrow \infty,
\end{gathered}
$$

where $T_{w}$ is the variable temperature at the sheet with $T_{0}$ being a constant which measures the rate of temperature increase along the sheet, $N_{w}$ is the variable wall nanoparticle volume fraction with $N_{0}$ being a constant, and $N_{\infty}$ is constant nanoparticle volume fraction in free stream. The stretching velocity $U_{w}$ is given by

$$
U_{w}(x)=c \exp \left(\frac{x}{L}\right)
$$

where $c>0$ is stretching constant. A physical model with the coordinate system of the problem is sketched in Figure 1.

Here $v_{w}$ is the variable wall mass transfer velocity and is given by

$$
v_{w}=v_{0} \exp \left(\frac{x}{2 L}\right)
$$

where $v_{0}$ is a constant with $v_{0}<0$ for mass suction and $v_{0}>0$ for mass injection.

Now, we introduce the similarity transformations:

$$
\begin{gathered}
\psi=\sqrt{2 v L c} f(\eta) \exp \left(\frac{x}{2 L}\right), \quad \theta(\eta)=\frac{T-T_{\infty}}{T_{w}-T_{\infty}}, \\
\varphi(\eta)=\frac{N-N_{\infty}}{N_{w}-N_{\infty}}, \quad \eta=y \sqrt{\frac{c}{2 v L}} \exp \left(\frac{x}{2 L}\right)
\end{gathered}
$$

where $\Psi$ is the stream function with $u=\partial \psi / \partial y$ and $v=$ $-\partial \psi / \partial x$ and $\eta$ is the similarity variable.

In view of relations in (6) we finally obtain the following self-similar equations:

$$
\begin{gathered}
f^{\prime \prime \prime}+f f^{\prime \prime}-2 f^{\prime 2}-M f^{\prime}=0, \\
\theta^{\prime \prime}+\operatorname{Pr}\left(f \theta^{\prime}-f^{\prime} \theta+\mathrm{Nb} \theta^{\prime} \varphi^{\prime}+\mathrm{Nt} \theta^{\prime 2}\right)=0, \\
\varphi^{\prime \prime}+\operatorname{Le}\left(f \varphi^{\prime}-f^{\prime} \varphi\right)+\frac{\mathrm{Nt}}{\mathrm{Nb}} \theta^{\prime \prime}=0,
\end{gathered}
$$




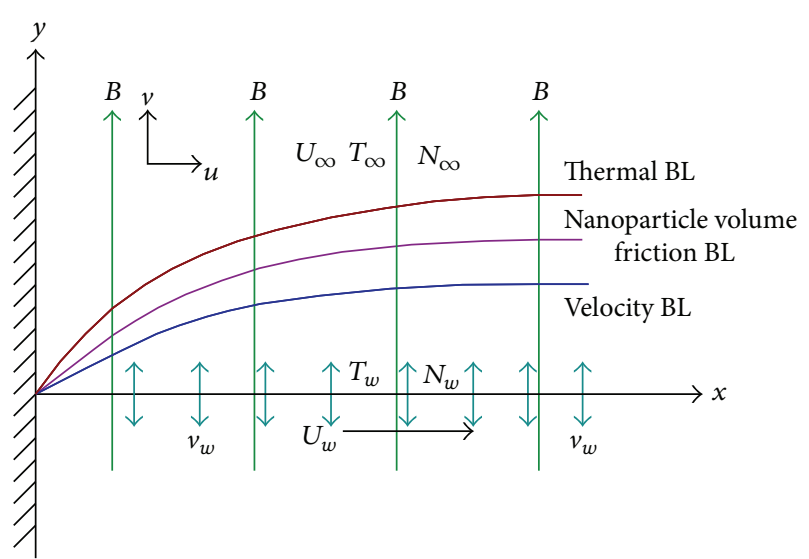

FIgURE 1: Physical model and coordinate system.

where $M=2 \sigma B_{0}^{2} L / c \rho$ is the magnetic parameter, $\operatorname{Pr}=v / \alpha$ is the Prandtl number, and Le $=v / D_{B}$ is the Lewis number. The dimensionless parameters $\mathrm{Nb}$ (Brownian motion parameter) and $\mathrm{Nt}$ (thermophoresis parameter) are defined as

$$
\begin{aligned}
& \mathrm{Nb}=D_{B} \frac{(\rho c)_{p}}{(\rho c)_{f}} \frac{\left(N_{w}-N_{\infty}\right)}{v}, \\
& \mathrm{Nt}=\frac{D_{T}}{T_{\infty}} \frac{(\rho c)_{p}}{(\rho c)_{f}} \frac{\left(T_{w}-T_{\infty}\right)}{v} .
\end{aligned}
$$
forms:

The boundary conditions (3) reduce to the following

$$
\begin{gathered}
f(\eta)=S, \quad f^{\prime}(\eta)=1 \quad \text { at } \eta=0, \\
f^{\prime}(\eta) \longrightarrow 0 \quad \text { as } \eta \longrightarrow \infty, \\
\theta(\eta)=1 \quad \text { at } \eta=0, \quad \theta(\eta) \longrightarrow 0 \quad \text { as } \eta \longrightarrow \infty, \\
\varphi(\eta)=1 \quad \text { at } \eta=0, \quad \varphi(\eta) \longrightarrow 0 \quad \text { as } \eta \longrightarrow \infty,
\end{gathered}
$$

where $S=-v_{0} / \sqrt{v c / 2 L}$ is the wall mass transfer parameter. $S>0\left(v_{0}<0\right)$ corresponds to mass suction and $S<0\left(v_{0}>\right.$ $0)$ corresponds to mass injection.

The quantities of physical interest for this problem are the local skin friction coefficient $C_{f}$, the local Nusselt number $\mathrm{Nu}_{x}$, and the local Sherwood number $\mathrm{Sh}_{x}$, which are, respectively, defined as [35]

$$
\begin{gathered}
C_{f}=\left.\frac{v}{U_{w}^{2} e^{2 x / L}} \frac{\partial u}{\partial y}\right|_{y=0}, \quad \mathrm{Nu}_{x}=-\left.\frac{x}{\left(T_{w}-T_{\infty}\right)} \frac{\partial T}{\partial y}\right|_{y=0}, \\
\operatorname{Sh}_{x}=-\left.\frac{x}{\left(N_{w}-N_{\infty}\right)} \frac{\partial N}{\partial y}\right|_{y=0},
\end{gathered}
$$

that is,

$$
\begin{gathered}
\sqrt{2 \operatorname{Re}_{x}} C_{f}=f^{\prime \prime}(0), \quad \frac{\mathrm{Nu}_{x}}{\sqrt{2 \mathrm{Re}_{x}}}=-\sqrt{\frac{x}{2 L}} \theta^{\prime}(0), \\
\frac{\mathrm{Sh}_{x}}{\sqrt{2 \mathrm{Re}_{x}}}=-\sqrt{\frac{x}{2 L}} \varphi^{\prime}(0),
\end{gathered}
$$

where $\operatorname{Re}_{x}=U_{w} x / v$ is the local Reynolds number.

\section{Numerical Method for Solution}

The highly nonlinear coupled ODEs (7) along with the boundary conditions (9) form a two-point boundary value problem (BVP) and those are solved using shooting method [36-41]. The following first-order system is set:

$$
\begin{gathered}
f^{\prime}=p, \quad p^{\prime}=q, \quad q^{\prime}=2 p^{2}-f q+M p, \\
\theta^{\prime}=r, \quad r^{\prime}=-\operatorname{Pr}\left(f r-p \theta+\mathrm{Nb} r z+\mathrm{Nt} r^{2}\right), \\
\varphi^{\prime}=z, \quad z^{\prime}=-\operatorname{Le}(f z-p \varphi)-\frac{\mathrm{Nt}}{\mathrm{Nb}} r^{\prime},
\end{gathered}
$$

with the boundary conditions

$$
f(0)=S, \quad p(0)=1, \quad \theta(0)=1, \quad \varphi(0)=1 .
$$

The set of nonlinear first-order ordinary differential equations (12) with boundary conditions (13) have been solved by shooting method using the fourth-order Runge-Kutta algorithm with a systematic guessing of $q(0)$, that is, $f^{\prime \prime}(0)$, $r(0)$, that is, $\theta^{\prime}(0)$, and $z(0)$, that is, $\varphi^{\prime}(0)$. The step size is taken as $\Delta \eta=0.01$ and the suitable finite value of $\eta \rightarrow \infty$, $\eta_{\infty}$, is taken as 20 in all cases. The guess values $f^{\prime \prime}(0), \theta^{\prime}(0)$, and $\varphi^{\prime}(0)$ are adjusted using "secant method" to give better approximation for the solution. An asymptotic convergence criterion of $10^{-5}$ level for the boundary conditions $f^{\prime}\left(\eta_{\infty}\right)=0$, $\theta\left(\eta_{\infty}\right)=0$, and $\varphi\left(\eta_{\infty}\right)=0$ is taken in the computation.

\section{Results and Discussion}

The numerical solutions are obtained using the above numerical scheme for some values of the governing parameters, namely, the magnetic parameter $(M)$, the wall mass transfer parameter $(S)$, the Prandtl number $(\operatorname{Pr})$, the Lewis number (Le), Brownian motion parameter $(\mathrm{Nb})$, and thermophoresis parameter (Nt). Effects of $M, S, \operatorname{Pr}, \mathrm{Le}, \mathrm{Nb}$, and $\mathrm{Nt}$ on the steady boundary layer flow, heat transfer, and nanoparticle volume fraction over exponentially stretching sheet in nanofluid are discussed in detail.

To ensure the numerical accuracy, the values $f^{\prime \prime}(0)$ and $f(\infty)$ are compared with the results of Magyari and Keller [18] in Table 1 without magnetic field $(M=0)$ and with nonporous stretching sheet $(S=0)$ and those are found in excellent agreement. Thus, we are very much confident that the present results are accurate.

The nondimensional velocity $f^{\prime}(\eta)$, temperature $\theta(\eta)$, and nanoparticle volume fraction $\varphi(\eta)$ for various values 


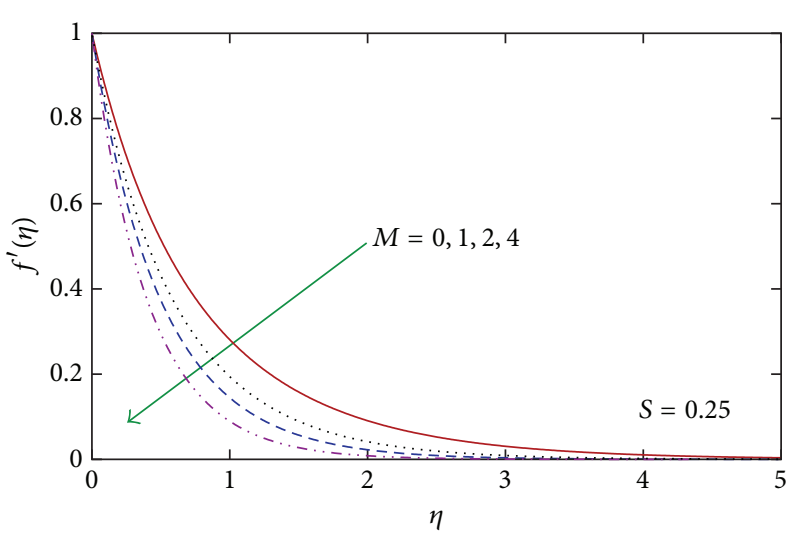

(a)

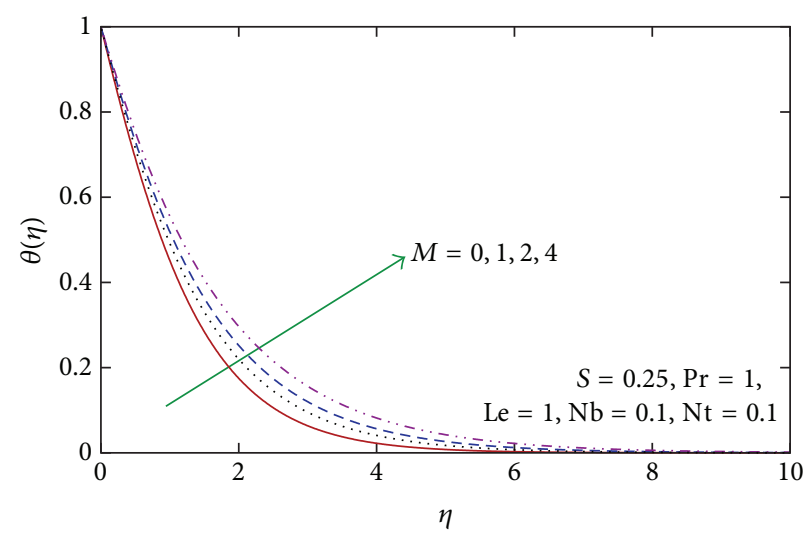

(b)

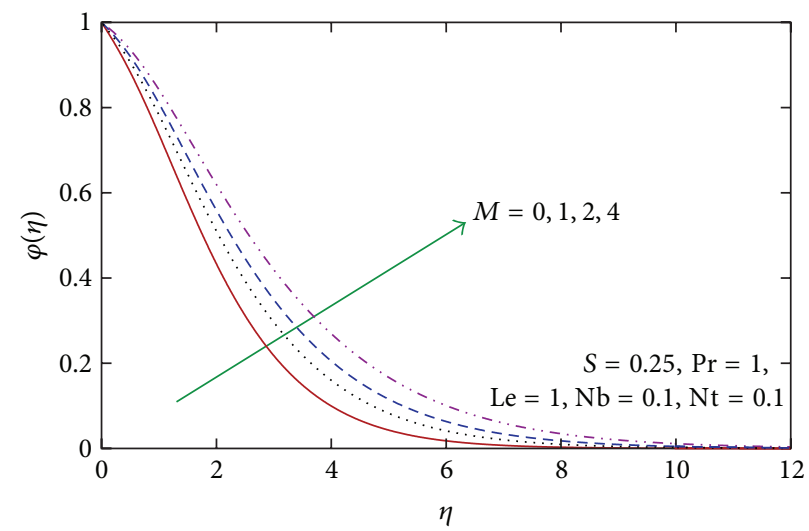

(c)

Figure 2: Effect of magnetic parameter $M$ on (a) velocity $f^{\prime}(\eta)$, (b) temperature $\theta(\eta)$, and (c) nanoparticle volume fraction $\varphi(\eta)$.

TABLE 1: The comparison of values of $f^{\prime \prime}(0)$ and $f(\infty)$ for $M=0$ and $S=0$.

\begin{tabular}{lcc}
\hline & Magyari and Keller [18] & Present study \\
\hline$-f^{\prime \prime}(0)$ & 1.281808 & 1.28180838 \\
$f(\infty)$ & 0.905639 & 0.90564328 \\
\hline
\end{tabular}

of magnetic parameter are shown in Figure 2. The velocity reduces with the increase of magnetic parameter. The magnetic field opposes the transport process. Actually, the increase of $M$ leads to the increase of the Lorentz force arising because of interaction of magnetic and electric fields for the motion of an electrically conducting fluid, and the stronger Lorentz force produces much more resistance to the transport phenomena. On the other hand, the temperature and the nanoparticle volume fraction increase with $M$. The Lorentz force has the tendency to increase the temperature and nanoparticle volume fraction in nanofluid motion. Consequently, the thermal boundary layer thickness and nanoparticle volume fraction boundary layer thickness become thicker for stronger magnetic field.

In Figure 3, the velocity, temperature, and nanoparticle volume fraction are presented for variation in wall mass transfer parameter $S$. With increasing values of the mass suction parameter $(S>0)$, the velocity $f^{\prime}(\eta)$, temperature $\theta(\eta)$, and nanoparticle volume fraction $\varphi(\eta)$ in the boundary layer region decrease, whereas, due to the increase of mass injection $(S<0)$, all those increase. Due to mass suction, the fluid is brought closer to the sheet and it thins velocity boundary layer thickness as well as the thermal and nanoparticle volume boundary layer thicknesses. Opposite effect is found for mass injection case; that is, the fluid is taken away from the sheet. Consequently, the velocity, thermal, and nanoparticle volume boundary layer thicknesses become broader.

The influences of the Prandtl number Pr and the Lewis number Le on the temperature and nanoparticle volume fraction are depicted in Figures 4 and 5, respectively. The increment of Prandtl number results in major effects on temperature as well as on nanoparticle volume fraction. The thermal boundary layer thickness reduces with Prandtl number and it happens due to decrease of thermal diffusivity for the increment of Prandtl number. The nanoparticle volume fraction exhibits overshoot near the sheet for higher values of $\mathrm{Pr}$, though the nanoparticle volume boundary layer thickness reduces. Hence, with uniform thermophoretic particle deposition, for larger values of Prandtl number the nanoparticle volume fraction $\varphi(\eta)$ is higher in the fluid adjacent to the sheet than the value at the wall. Very minor variation (initially increasing near the sheet and then decreasing away from the sheet) is observed in the temperature with the increase in the Lewis number. For large values of 


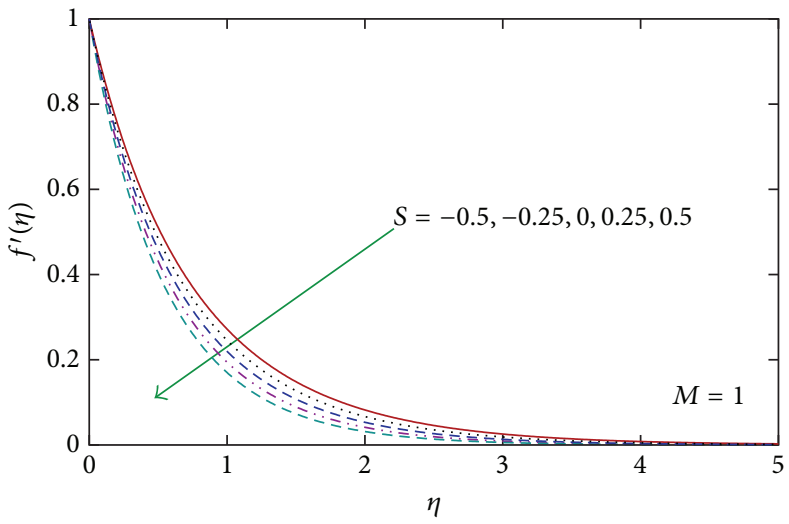

(a)

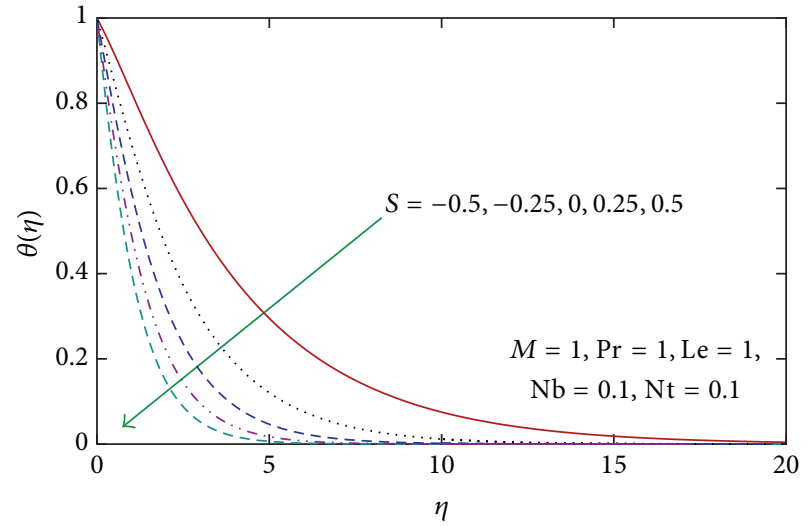

(b)

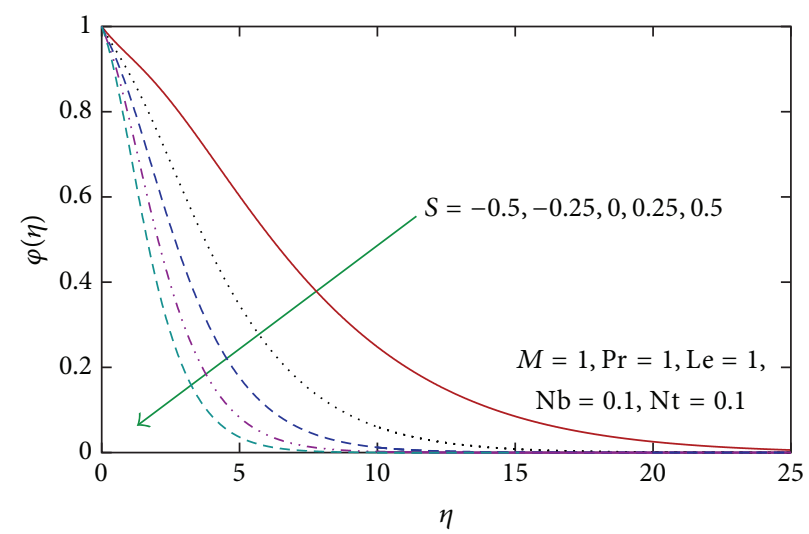

(c)

FIGURE 3: Effect of mass transfer parameter $S$ on (a) velocity $f^{\prime}(\eta)$, (b) temperature $\theta(\eta)$, and (c) nanoparticle volume fraction $\varphi(\eta)$.

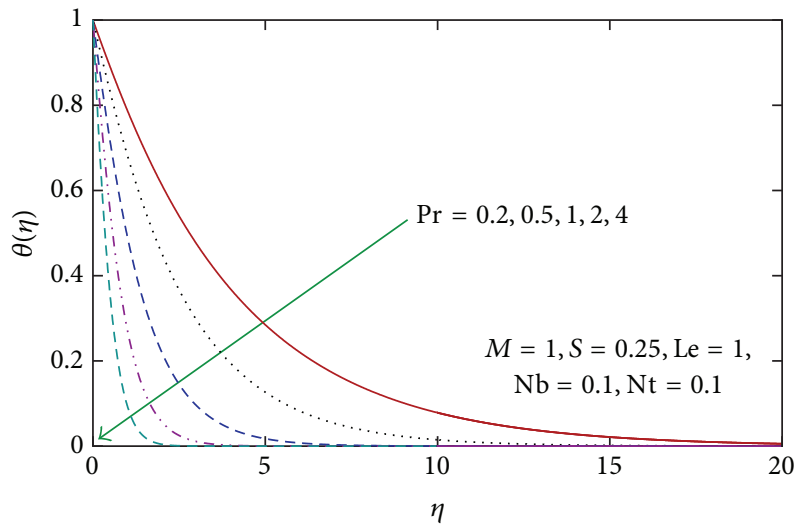

(a)

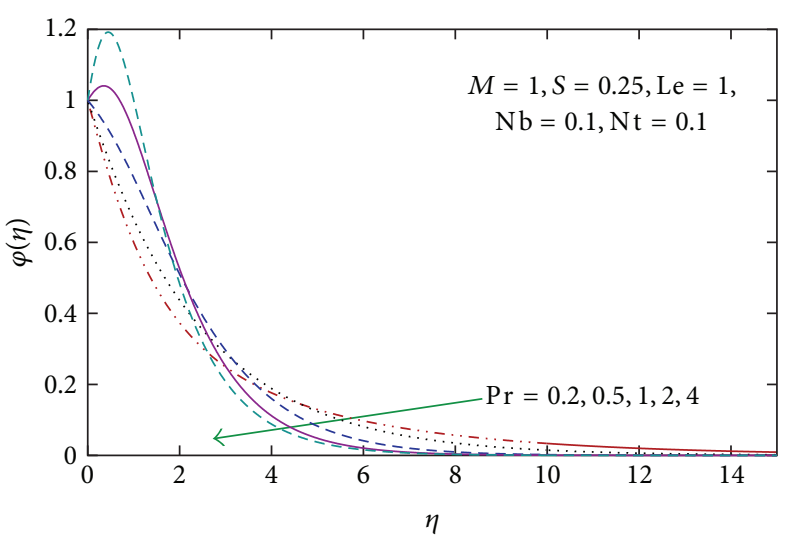

(b)

Figure 4: Effect of Prandtl number Pr on (a) temperature $\theta(\eta)$ and (b) nanoparticle volume fraction $\varphi(\eta)$.

Le, the nanoparticle volume fraction significantly decreases and also the nanoparticle volume boundary layer thickness reduces. But, for smaller value of Le the overshoot is found in $\varphi(\eta)$ near the sheet (Figure 5(b)). The Brownian diffusion effect becomes nominal for larger values of Lewis number and for which the nanoparticle volume boundary layer thickness decreases.
The effect of Brownian motion parameter $\mathrm{Nb}$ on the dimensionless temperature and the dimensionless nanoparticle volume fraction is plotted in Figure 6 (Figures 6(a) and 6 (b), respectively). The figure reveals that the temperature of the fluid increases and the nanoparticle volume fraction decreases with increasing values of $\mathrm{Nb}$. In nanofluid system, due to the presence of nanoparticles, the Brownian motion 


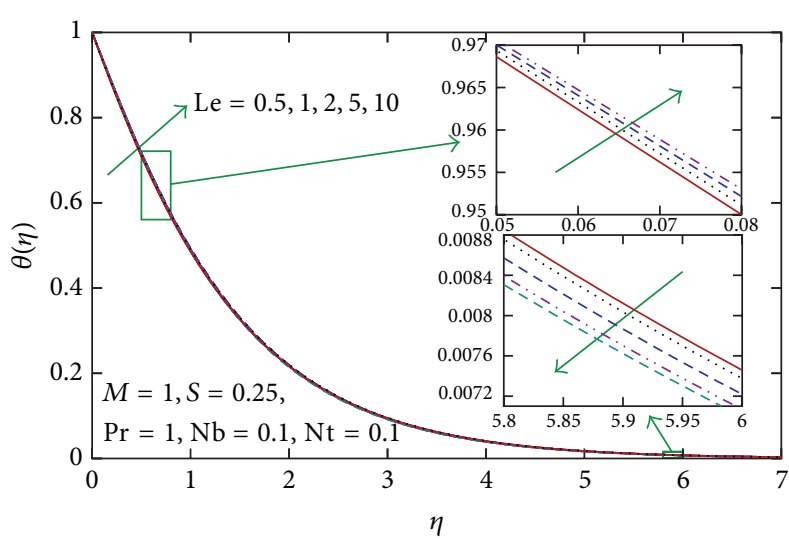

(a)

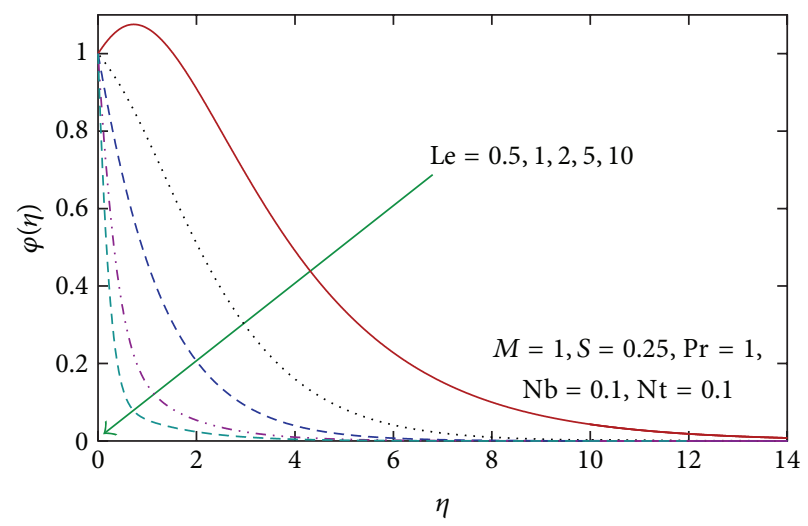

(b)

FIGURE 5: Effect of Lewis number Le on (a) temperature $\theta(\eta)$ and (b) nanoparticle volume fraction $\varphi(\eta)$.

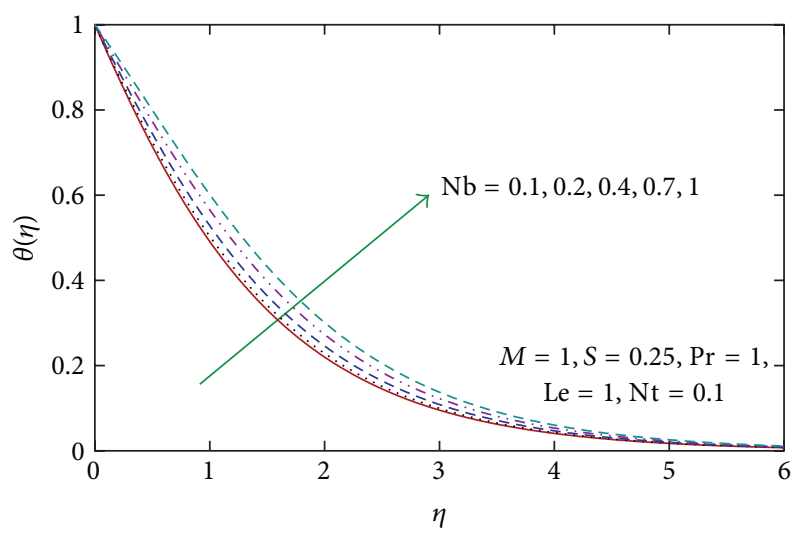

(a)

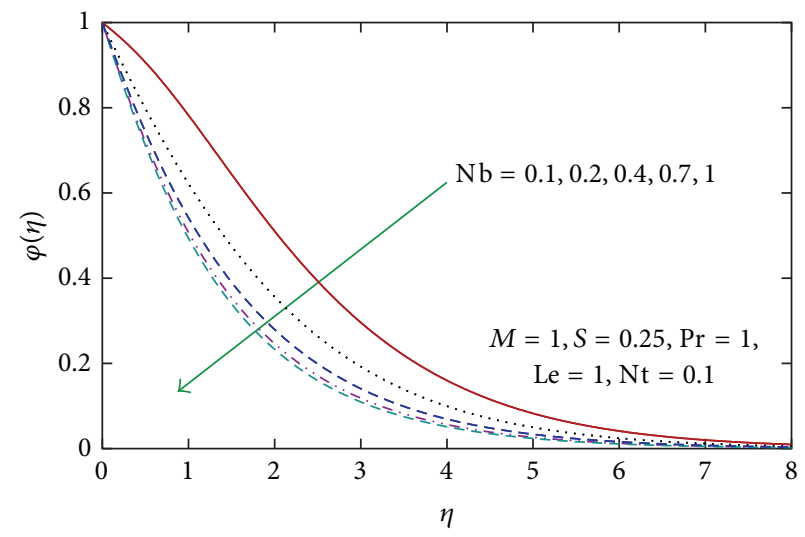

(b)

FIGURE 6: Effect of Brownian motion parameter $\mathrm{Nb}$ on (a) temperature $\theta(\eta)$ and (b) nanoparticle volume fraction $\varphi(\eta)$.

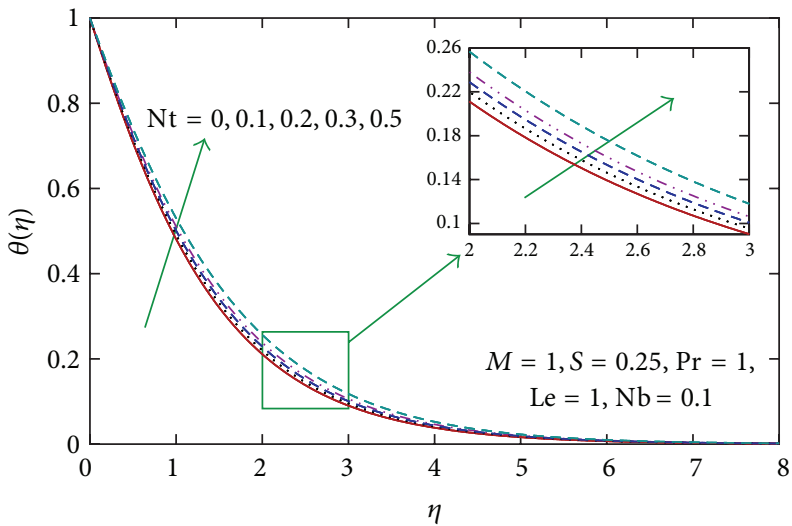

(a)

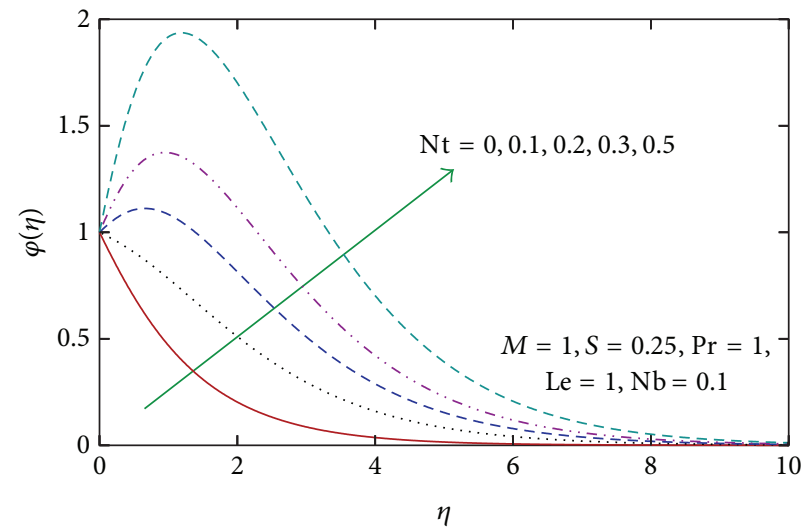

(b)

FIGURE 7: Effect of thermophoresis parameter $\mathrm{Nt}$ on (a) temperature $\theta(\eta)$ and (b) nanoparticle volume fraction $\varphi(\eta)$.

takes place and for the increase in $\mathrm{Nb}$ the Brownian motion is affected and consequently the heat transfer characteristic of the fluid changes. Also, when the value of $\mathrm{Nb}$ increases, the nanoparticle volume boundary layer thickness decreases.

Thermophoresis parameter $\mathrm{Nt}$ is a key parameter for analysing the temperature distributions and nanoparticles volume fraction in nanofluid flow. The effect of thermophoresis parameter Nt on the temperature $\theta(\eta)$ and the nanoparticle volume fraction $\varphi(\eta)$ is presented in Figure 7. With increase of $\mathrm{Nt}$, the temperature of the fluid increases. The nanoparticle volume fraction increases with $\mathrm{Nt}$ and the overshoot near the wall is found. Increase in $\mathrm{Nt}$ causes 


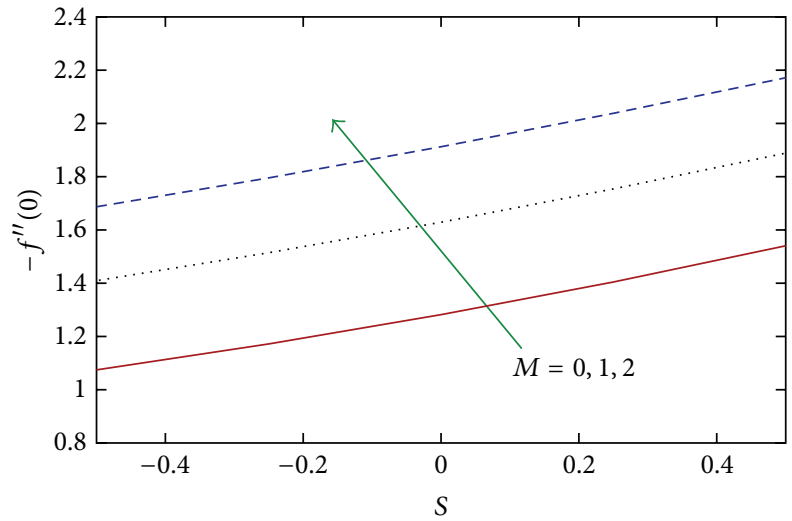

(a)

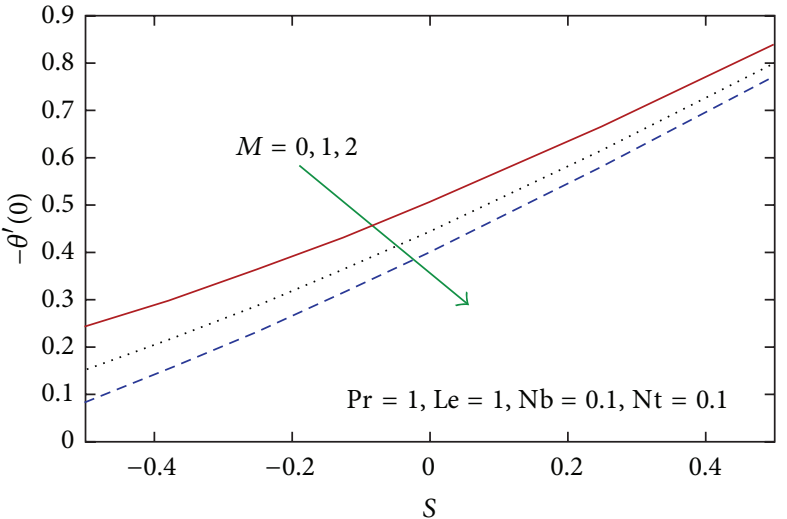

(b)

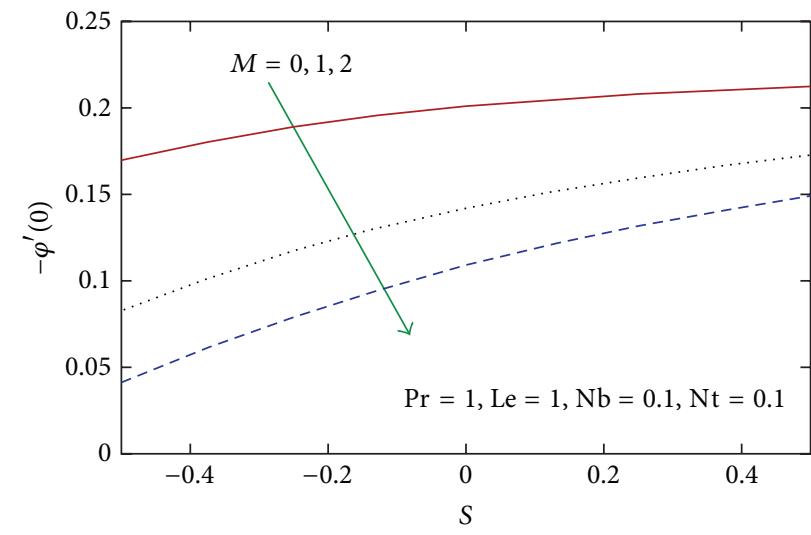

(c)

FIGURE 8: Variations of (a) $-f^{\prime \prime}(\eta),(\mathrm{b})-\theta^{\prime}(0)$, and (c) $-\varphi^{\prime}(0)$ for different values of magnetic parameter $M$ and mass transfer parameter $S$.

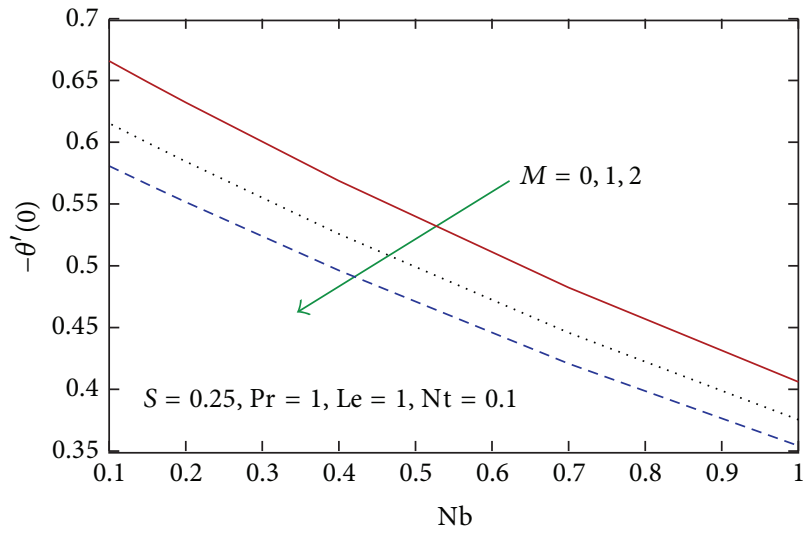

(a)

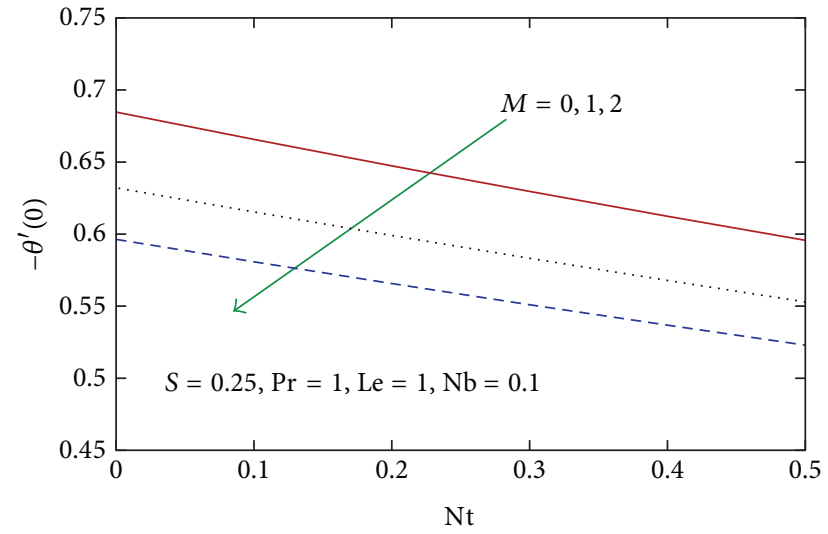

(b)

FIGURE 9: Variation of $-\theta^{\prime}(0)$ with (a) Brownian motion parameter $\mathrm{Nb}$ and (b) thermophoresis parameter Nt, for different values of magnetic parameter $M$.

increment in the thermophoresis force which tends to move nanoparticles from hot to cold areas and consequently it increases the magnitude of temperature profiles and nanoparticle volume fraction profiles. Ultimately, the thickness of nanoparticle volume boundary layer becomes significantly large for slightly increased value of thermophoresis parameter.

We now discuss the variations of the physical quantities of engineering importance, that is, the local skin friction coefficient $C_{f}$, the local Nusselt number $\mathrm{Nu}_{x}$, and the local 
Sherwood number $S h_{x}$ for different values of $M, S, \operatorname{Pr}$, Le, $\mathrm{Nb}$, and $\mathrm{Nt}$. And for which the quantities $-f^{\prime \prime}(0),-\theta^{\prime}(0)$, and $-\varphi^{\prime}(0)$ related to local skin friction coefficient, the local Nusselt number and the local Sherwood number, respectively, are plotted in Figures 8, 9, 10, 11, 12, 13, 14, 15, and 16 for various values of parameters. The values of $-f^{\prime \prime}(0),-\theta^{\prime}(0)$, and $-\varphi^{\prime}(0)$ versus the mass transfer parameter $S$ are plotted in Figure 8 for different values magnetic parameter. For stronger magnetic field the value of $-f^{\prime \prime}(0)$, that is, the local skin friction coefficient, increases, whereas the values of $-\theta^{\prime}(0)$, that is, local Nusselt number, and $-\varphi^{\prime}(0)$, that is, local Sherwood number, decreases. Also, the values of $-\theta^{\prime}(0)$ and $-\varphi^{\prime}(0)$ are depicted against Brownian motion parameter $\mathrm{Nb}$ and thermophoresis parameter $\mathrm{Nt}$ for various $M$ in Figures 9 and 10. Similar results are also observed in those graphs. In physical viewpoint, it can be noticed that the powerful Lorentz force that arose in flow field for larger magnetic field reduces the values of local Nusselt number and local Sherwood number. On the other hand, the skin friction coefficient increases (decreases) with mass suction (injection) (Figure 8(a)), $-\theta^{\prime}(0)$ and $-\varphi^{\prime}(0)$ are displayed against $\mathrm{Nb}$ and $\mathrm{Nt}$ for several $S$ in Figures 11 and 12. From all graphical results it should be noted that, similar to that of skin friction, the local Nusselt number and the local Sherwood number also decrease with injection and increase with suction. But for greater values of thermophoresis parameter $\mathrm{Nt}$, the contrary effect of mass transfer parameter on the local Sherwood number is obtained, namely, the value of $-\varphi^{\prime}(0)$ increases with mass injection and decreases with mass suction (Figure 12(b)). The effects of Prandtl number $\operatorname{Pr}$ and Lewis number Le on the local Nusselt number $\mathrm{Nu}_{x}$ and the local Sherwood number $\mathrm{Sh}_{x}$ are illustrated in Figures 13-16. Due to higher values of Prandtl number the local Nusselt number increases and local Sherwood number reduces. The heat transfer rate is strengthened when the Prandtl number increases, whereas it is worth noting that the Lewis number affects the Nusselt number (reduction) and the Sherwood number (increment) in completely reverse manner compared to that of Prandtl number. For small values of Lewis number, the Brownian diffusion effect is large and accordingly increased heat transfer rate is found (greater Nusselt number, Figure 15(a)). From Figures 9 to 16, the variations in local Nusselt number and the local Sherwood number for Brownian motion parameter $\mathrm{Nb}$ and thermophoresis parameter Nt can be understood. For high rate of Brownian motion, that is, for increasing $\mathrm{Nb}$, the values of $-\theta^{\prime}(0)$ reduce and those of $-\varphi^{\prime}(0)$ increase. But the increase in thermophoresis parameter $\mathrm{Nt}$ causes reduction in both, the local Nusselt number and the local Sherwood number.

\section{Concluding Remarks}

The laminar MHD boundary layer flow of nanofluid past an exponentially permeable stretching sheet has been studied. The spatial focus is offered to the effects of Brownian motion and thermophoresis on the heat transfer in boundary layer flow of nanofluid due to an exponentially stretching sheet in presence of magnetic field. The findings of the analysis can be summarized as follows.

(a) Due to thermophoresis particle deposition and Brownian motion the heat transfer from the surface to the ambient fluid significantly increases.

(b) The temperature and the nanoparticle volume fraction are enhanced with thermophoresis.

(c) For Brownian motion the temperature of the fluid increases and the nanoparticle volume fraction decreases.

(d) Due to the presence of the nanoparticles in the fluid, the Brownian motion and thermophoresis take place and those cause significant change in the heat transfer efficiency of the fluid.

(e) The magnetic field reduces the heat transfer rate, though it causes the increment in the temperature and the nanoparticle volume fraction inside the boundary layer due to exponential stretching of sheet.

(f) Due to mass suction, the velocity boundary layer thickness as well as the thermal and nanoparticle volume boundary layer thicknesses becomes thinner, whereas mass injection makes those thicker.

\section{Nomenclature}

$B$ : Variable magnetic field

$B_{0}$ : A constant

$c$ : Stretching constant

$C_{f}:$ Local skin friction coefficient

$D_{B}$ : Brownian diffusion coefficient

$D_{T}$ : Thermophoretic diffusion coefficient

$f:$ Dimensionless stream function

$f^{\prime}$ : Dimensionless velocity

Le: Lewis number

M: Magnetic parameter

$N$ : Nanoparticle volume fraction

$N_{\infty}$ : Constant nanoparticle volume fraction in free stream

$N_{w}$ : Variable wall nanoparticle volume fraction

$N_{0}$ : A constant

$\mathrm{Nb}$ : Brownian motion parameter

Nt: Thermophoresis parameter

$\mathrm{Nu}_{x}$ : Local Nusselt number

$p: \quad$ A variable

Pr: Prandtl number

q: A variable

$\mathrm{Re}_{x}$ : Local Reynolds number

$S: \quad$ Wall mass transfer parameter

$\mathrm{Sh}_{x}:$ Local Sherwood number

$T: \quad$ Temperature

$T_{\infty}$ : Constant temperature of the fluid in the free stream

$T_{w}$ : Variable temperature at the sheet

$T_{0}$ : A constant

$u$ : Velocity component in $x$-direction

$U_{w}$ : Stretching velocity

$v$ : Velocity component in $y$-direction 


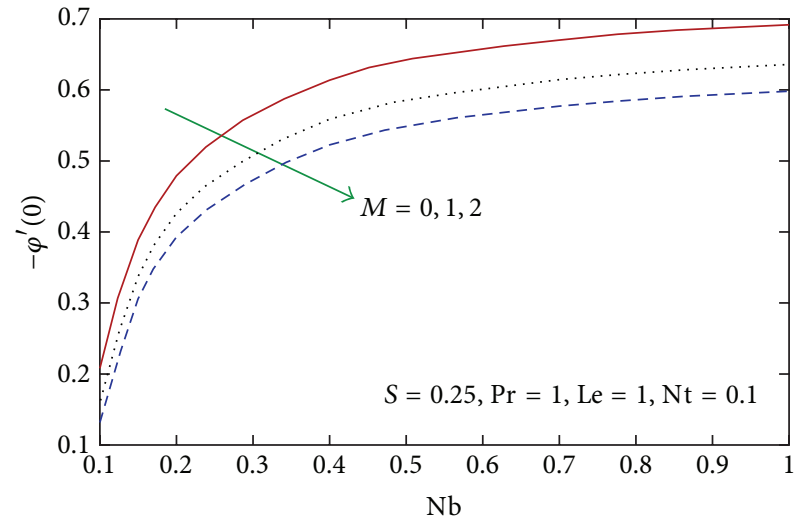

(a)

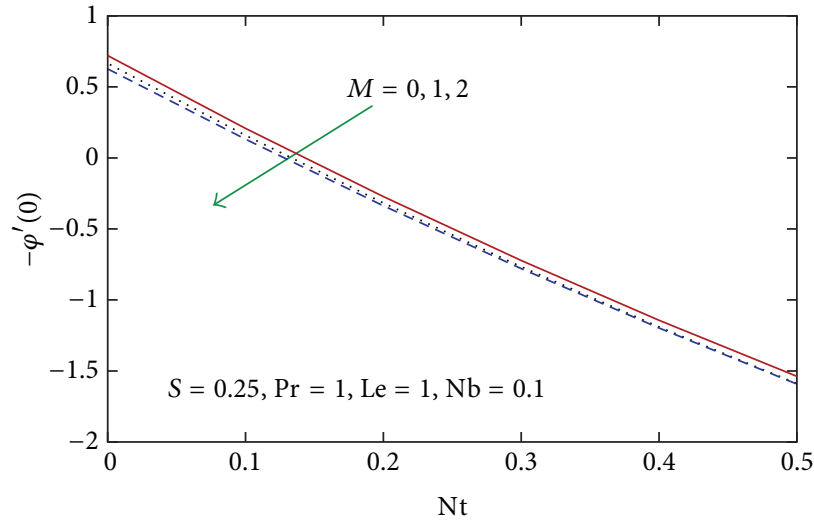

(b)

FIGURE 10: Variation of $-\varphi^{\prime}(0)$ with (a) Brownian motion parameter $\mathrm{Nb}$ and (b) thermophoresis parameter $\mathrm{Nt}$, for different values of magnetic parameter $M$.

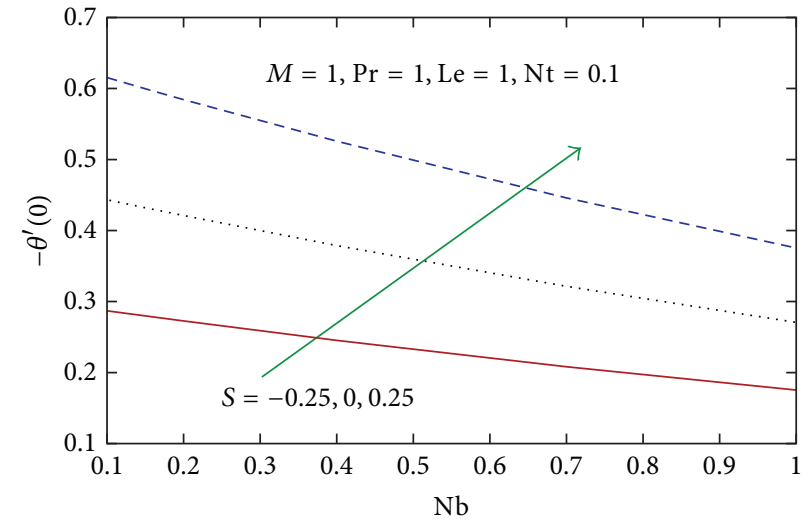

(a)

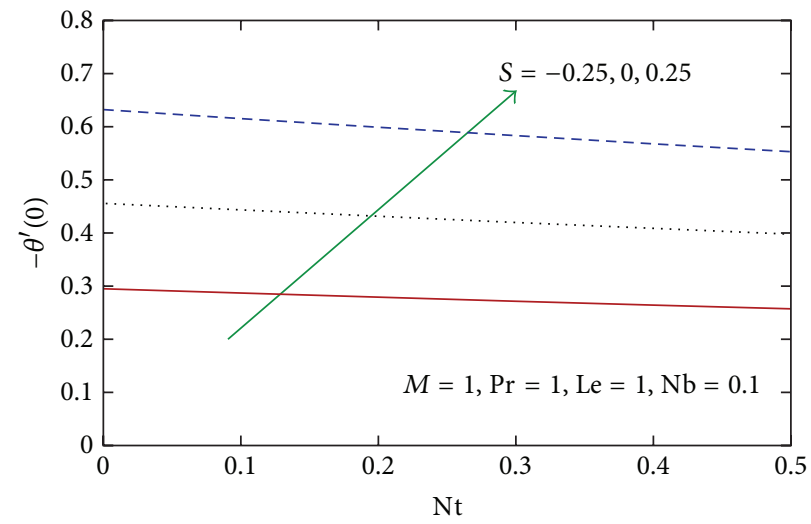

(b)

Figure 11: Variation of $-\theta^{\prime}(0)$ with (a) Brownian motion parameter $\mathrm{Nb}$ and (b) thermophoresis parameter Nt, for different values of mass transfer parameter $S$.

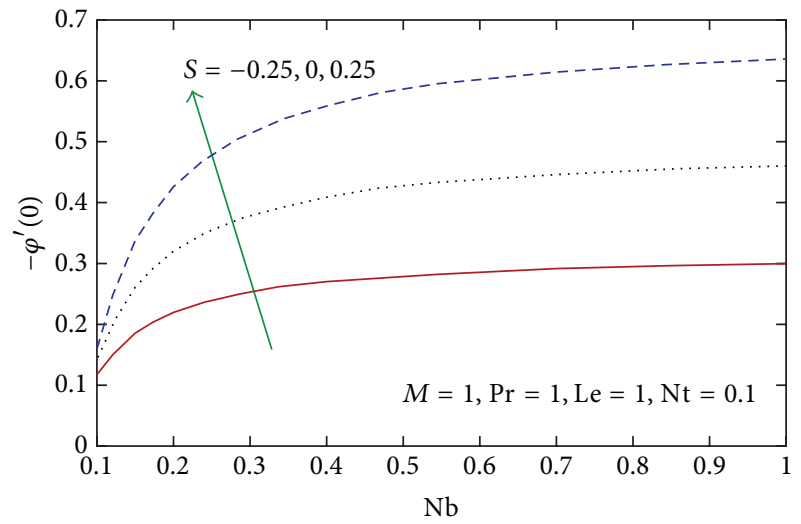

(a)

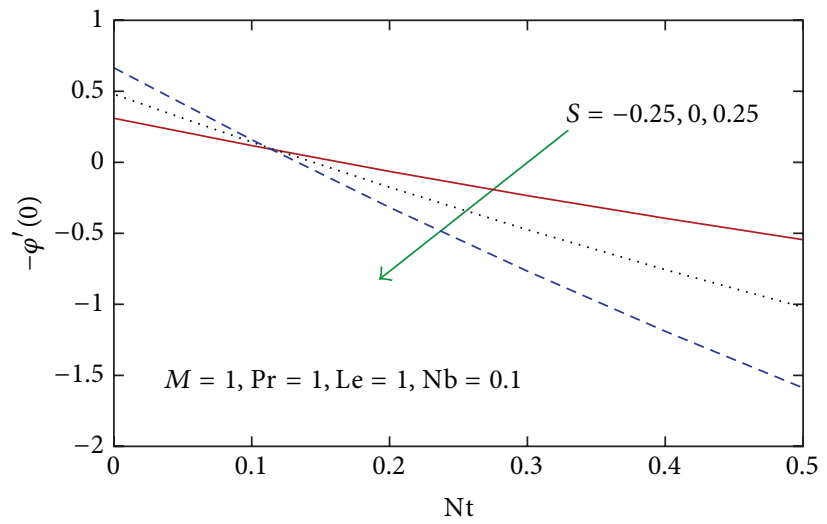

(b)

Figure 12: Variation of $-\varphi^{\prime}(0)$ with (a) Brownian motion parameter Nb and (b) thermophoresis parameter Nt, for different values of mass transfer parameter $S$. 


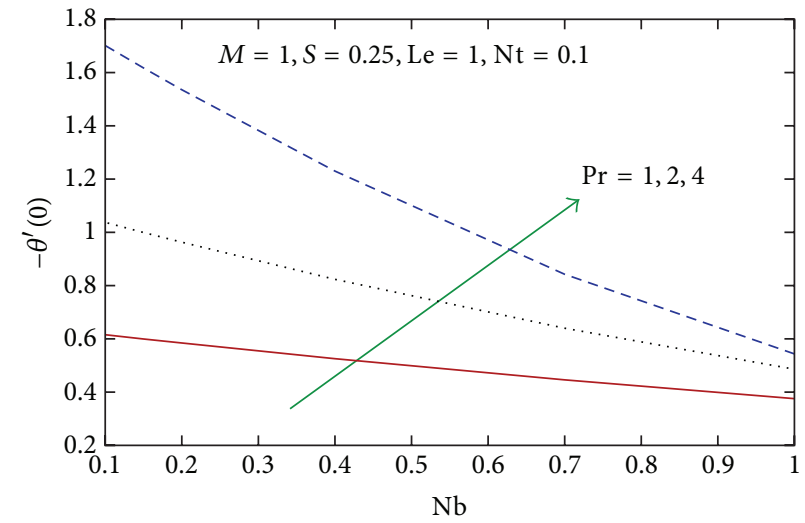

(a)

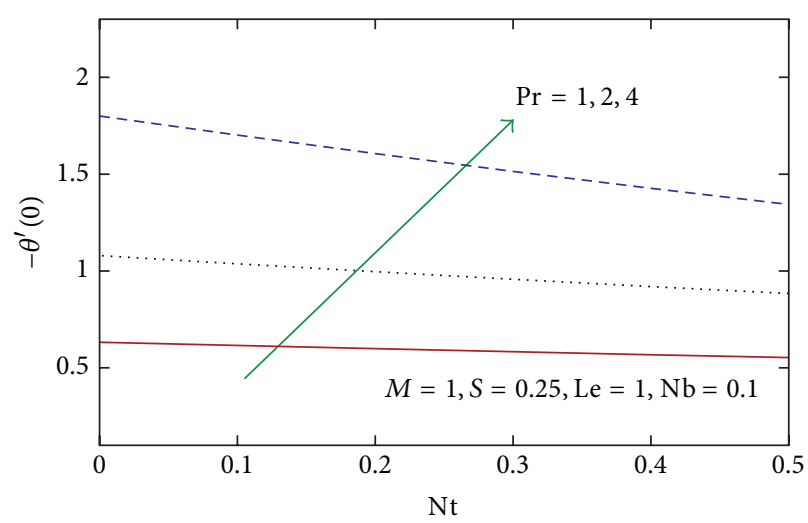

(b)

FIGURE 13: Variation of $-\theta^{\prime}(0)$ with (a) Brownian motion parameter $\mathrm{Nb}$ and (b) thermophoresis parameter Nt, for different values of Prandtl number Pr.

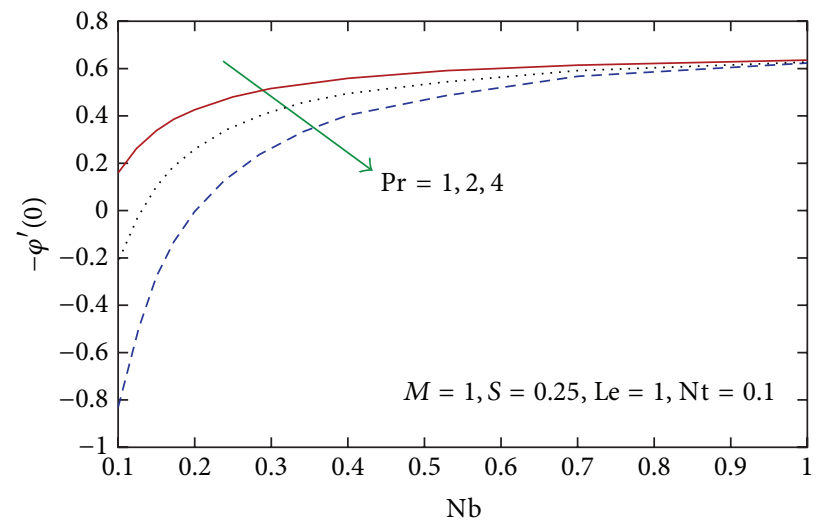

(a)

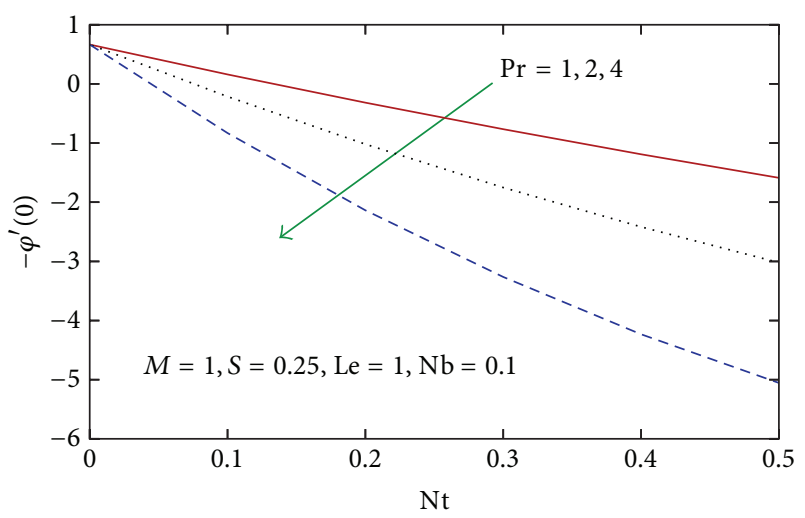

(b)

FIGURE 14: Variation of $-\varphi^{\prime}(0)$ with (a) Brownian motion parameter $\mathrm{Nb}$ and (b) thermophoresis parameter Nt, for different values of Prandtl number Pr.

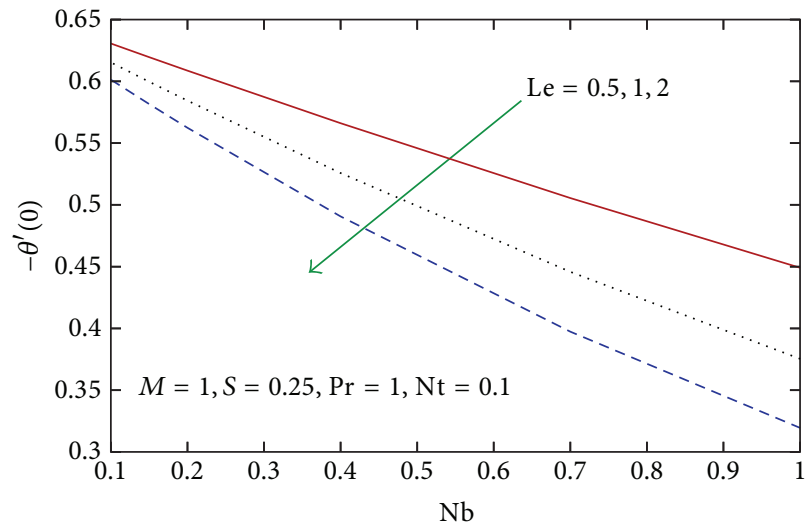

(a)

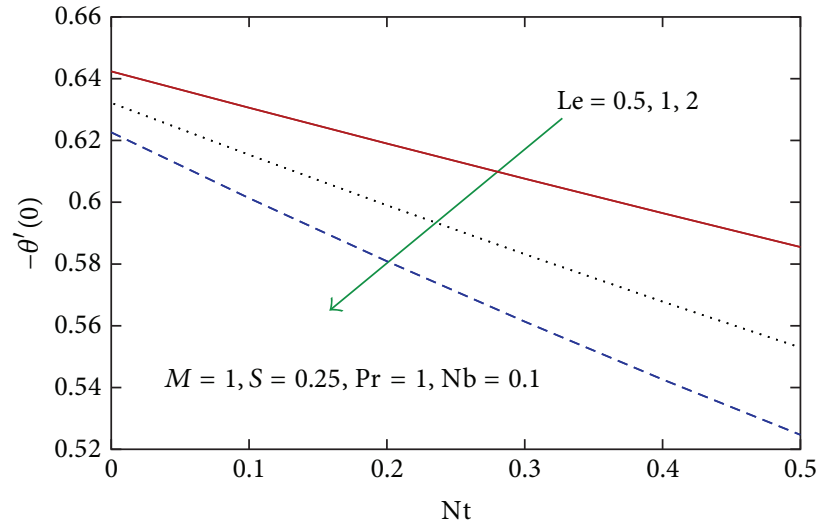

(b)

FIGURE 15: Variation of $-\theta^{\prime}(0)$ with (a) Brownian motion parameter $\mathrm{Nb}$ and (b) thermophoresis parameter $\mathrm{Nt}$, for different values of Lewis number Le. 


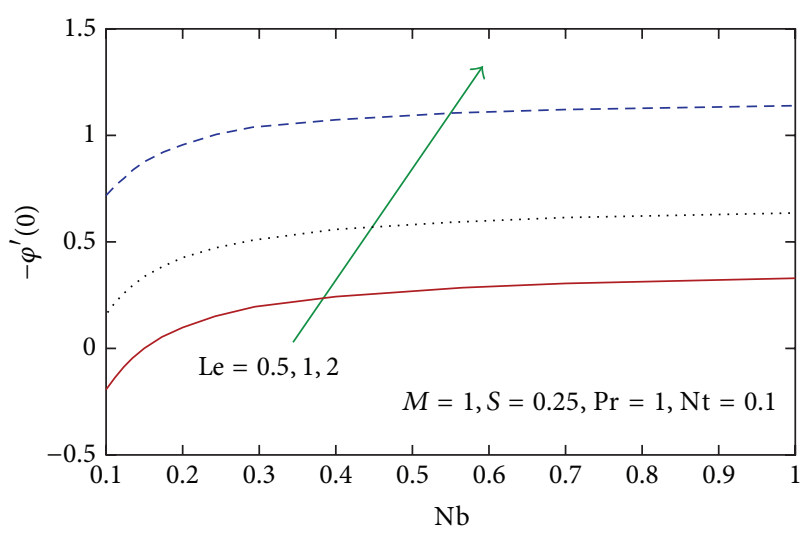

(a)

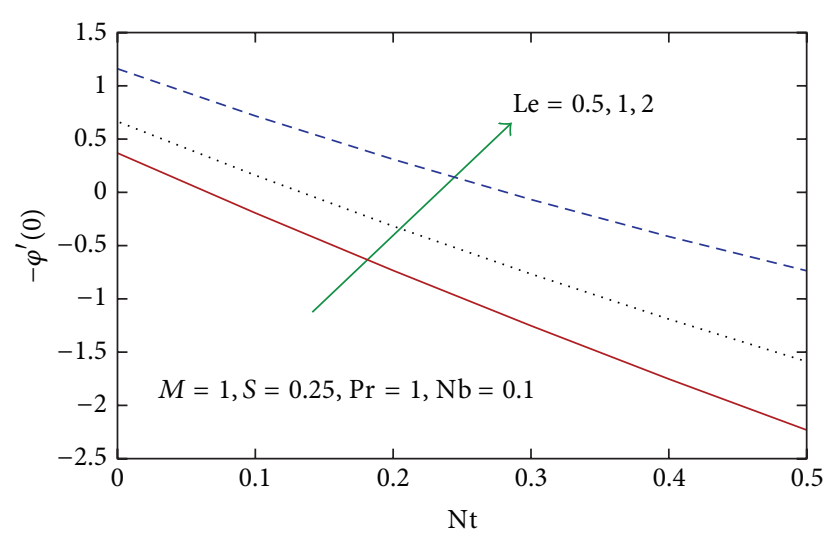

(b)

Figure 16: Variation of $-\varphi^{\prime}(0)$ with (a) Brownian motion parameter $\mathrm{Nb}$ and (b) thermophoresis parameter Nt, for different values of Lewis number Le.

$v_{w}:$ Variable wall mass transfer velocity

$v_{0}$ : A constant

$x$ : Distance along the sheet

$y$ : Distance perpendicular to the sheet

$z$ : A variable.

\section{Greek Symbols}

$\begin{array}{ll}\alpha: & \text { Thermal conductivity } \\ \eta: & \text { Similarity variable } \\ v: & \text { Kinematic viscosity } \\ \varphi: & \text { Dimensionless nanoparticle volume fraction } \\ \rho_{f}: & \text { Density of the base fluid } \\ (\rho c)_{p}: & \text { Effective heat capacity of nanoparticles } \\ (\rho c)_{f}: & \text { Heat capacity of the base fluid } \\ \Psi: & \text { Stream function } \\ \theta: & \text { Dimensionless temperature. }\end{array}$

\section{Conflict of Interests}

The authors declare that there is no conflict of interests regarding the publication of this paper.

\section{Acknowledgments}

One of the authors (Krishnendu Bhattacharyya) is grateful to the National Board for Higher Mathematics (NBHM), Department of Atomic Energy, Government of India, for the financial support in pursuing this work. The authors are thankful for the suggestions and comments of the referees, which have led to improvement of the paper.

\section{References}

[1] S. U. S. Choi, "Enhancing thermal conductivity of fluids with nanoparticles," in Proceedings of the ASME International Mechanical Engineering Congress and Exposition, vol. 66, pp. 99-105, San Francisco, Calif, USA, November 1995.
[2] H. Masuda, A. Ebata, K. Teramae, and N. Hishinuma, "Alteration of thermal conductivity and viscosity of liquid by dispersing ultra-fine particles," Netsu Bussei, vol. 7, pp. 227-233, 1993.

[3] J. Buongiorno, "Convective transport in nanofluids," Journal of Heat Transfer, vol. 128, no. 3, pp. 240-250, 2006.

[4] D. A. Nield and A. V. Kuznetsov, "The Cheng-Minkowycz problem for natural convective boundary-layer flow in a porous medium saturated by a nanofluid," International Journal of Heat and Mass Transfer, vol. 52, no. 25-26, pp. 5792-5795, 2009.

[5] A. V. Kuznetsov and D. A. Nield, "Natural convective boundarylayer flow of a nanofluid past a vertical plate," International Journal of Thermal Sciences, vol. 49, no. 2, pp. 243-247, 2010.

[6] L. J. Crane, "Flow past a stretching plate," Zeitschrift für Angewandte Mathematik und Physik ZAMP, vol. 21, no. 4, pp. 645-647, 1970.

[7] P. S. Gupta and A. S. Gupta, "Heat and mass transfer on a stretching sheet with suction and blowing," The Canadian Journal of Chemical Engineering, vol. 55, no. 6, pp. 744-746, 1977.

[8] B. K. Dutta, P. Roy, and A. S. Gupta, "Temperature field in flow over a stretching sheet with uniform heat flux," International Communications in Heat and Mass Transfer, vol. 12, no. 1, pp. 89-94, 1985.

[9] H. I. Andersson and B. S. Dandapat, "Flow of a power-law fluid over a stretching sheet," Stability and Applied Analysis of Continuous Media, vol. 1, pp. 339-347, 1991.

[10] R. Cortell, "Viscous flow and heat transfer over a nonlinearly stretching sheet," Applied Mathematics and Computation, vol. 184, no. 2, pp. 864-873, 2007.

[11] K. Bhattacharyya and G. C. Layek, "Chemically reactive solute distribution in MHD boundary layer flow over a permeable stretching sheet with suction or blowing," Chemical Engineering Communications, vol. 197, no. 12, pp. 1527-1540, 2010.

[12] K. Bhattacharyya, S. Mukhopadhyay, and G. C. Layek, "Slip effects on an unsteady boundary layer stagnation-point flow and heat transfer towards a stretching sheet," Chinese Physics Letters, vol. 28, no. 9, Article ID 094702, 2011.

[13] K. Bhattacharyya and G. C. Layek, "Slip effect on diffusion of chemically reactive species in boundary layer flow over a vertical stretching sheet with suction or blowing," Chemical Engineering Communications, vol. 198, no. 11, pp. 1354-1365, 2011. 
[14] K. Bhattacharyya, "Effects of radiation and heat source/sink on unsteady MHD boundary layer flow and heat transfer over a shrinking sheet with suction/injection," Frontiers of Chemical Science and Engineering, vol. 5, no. 3, pp. 376-384, 2011.

[15] K. Bhattacharyya, M. G. Arif, and W. Ali Pramanik, "MHD boundary layer stagnation-point flow and mass transfer over a permeable shrinking sheet with suction/blowing and chemical reaction," Acta Technica, vol. 57, pp. 1-15, 2012.

[16] K. Bhattacharyya, S. Mukhopadhyay, and G. C. Layek, "Unsteady MHD boundary layer flow with diffusion and first order chemical reaction over a permeable stretching sheet with suction or blowing," Chemical Engineering Communications, vol. 200, no. 3, pp. 379-397, 2013.

[17] K. Bhattacharyya, "Heat transfer in unsteady boundary layer stagnation-point flow towards a shrinking sheet," Ain Shams Engineering Journal, vol. 4, no. 2, pp. 259-264, 2013.

[18] E. Magyari and B. Keller, "Heat and mass transfer in the boundary layers on an exponentially stretching continuous surface," Journal of Physics D, vol. 32, no. 5, pp. 577-585, 1999.

[19] E. M. A. Elbashbeshy, "Heat transfer over an exponentially stretching continuous surface with suction," Archives of Mechanics, vol. 53, no. 6, pp. 643-651, 2001.

[20] S. K. Khan and E. Sanjayanand, "Viscoelastic boundary layer flow and heat transfer over an exponential stretching sheet," International Journal of Heat and Mass Transfer, vol. 48, no. 8, pp. 1534-1542, 2005.

[21] M. K. Partha, P. V. S. N. Murthy, and G. P. Rajasekhar, "Effect of viscous dissipation on the mixed convection heat transfer from an exponentially stretching surface," Heat and Mass Transfer, vol. 41, no. 4, pp. 360-366, 2005.

[22] A. Ishak, "MHD boundary layer flow due to an exponentially stretching sheet with radiation effect," Sains Malaysiana, vol. 40, no. 4, pp. 391-395, 2011.

[23] K. Bhattacharyya, "Boundary layer flow and heat transfer over an exponentially shrinking sheet," Chinese Physics Letters, vol. 28, no. 7, Article ID 074701, 2011.

[24] K. Bhattacharyya and I. Pop, "MHD boundary layer flow due to an exponentially shrinking sheet," Magnetohydrodynamics, vol. 47, pp. 337-344, 2011.

[25] K. Bhattacharyya and K. Vajravelu, "Stagnation-point flow and heat transfer over an exponentially shrinking sheet," Communications in Nonlinear Science and Numerical Simulation, vol. 17, no. 7, pp. 2728-2734, 2012.

[26] N. Bachok, A. Ishak, and I. Pop, "Boundary layer stagnationpoint flow and heat transfer over an exponentially stretching/shrinking sheet in a nanofluid," International Journal of Heat and Mass Transfer, vol. 55, no. 25-26, pp. 8122-8128, 2012.

[27] W. A. Khan and I. Pop, "Boundary-layer flow of a nanofluid past a stretching sheet," International Journal of Heat and Mass Transfer, vol. 53, no. 11-12, pp. 2477-2483, 2010.

[28] O. D. Makinde and A. Aziz, "Boundary layer flow of a nanofluid past a stretching sheet with a convective boundary condition," The International Journal of Thermal Sciences, vol. 50, no. 7, pp. 1326-1332, 2011.

[29] R. Kandasamy, P. Loganathan, and P. Puvi Arasu, "Scaling group transformation for MHD boundary-layer flow of a nanofluid past a vertical stretching surface in the presence of suction/injection," Nuclear Engineering and Design, vol. 241, no. 6, pp. 2053-2059, 2011.

[30] M. Mustafa, T. Hayat, I. Pop, S. Asghar, and S. Obaidat, "Stagnation-point flow of a nanofluid towards a stretching sheet," International Journal of Heat and Mass Transfer, vol. 54, no. 25-26, pp. 5588-5594, 2011.

[31] P. Rana and R. Bhargava, "Flow and heat transfer of a nanofluid over a nonlinearly stretching sheet: a numerical study," Communications in Nonlinear Science and Numerical Simulation, vol. 17, no. 1, pp. 212-226, 2012.

[32] F. M. Hady, F. S. Ibrahim, S. M. Abdel-Gaied, and M. R. Eid, "Radiation effect on viscous flow of a nanofluid and heat transfer over a nonlinearly stretching sheet," Nanoscale Research Letters, vol. 7, article 229, 2012.

[33] O. D. Makinde, W. A. Khan, and Z. H. Khan, "Buoyancy effects on MHD stagnation point flow and heat transfer of a nanofluid past a convectively heated stretching/shrinking sheet," International Journal of Heat and Mass Transfer, vol. 62, pp. 526-533, 2013.

[34] N. Bachok, A. Ishak, and I. Pop, "Unsteady boundary-layer flow and heat transfer of a nanofluid over a permeable stretching/shrinking sheet," International Journal of Heat and Mass Transfer, vol. 55, no. 7-8, pp. 2102-2109, 2012.

[35] S. Nadeem and C. Lee, "Boundary layer flow of nanofluid over an exponentially stretching surface," Nanoscale Research Letters, vol. 7, article 94, pp. 1-15, 2012.

[36] K. Bhattacharyya, S. Mukhopadhyay, and G. C. Layek, "MHD boundary layer slip flow and heat transfer over a flat plate," Chinese Physics Letters, vol. 28, no. 2, Article ID 024701, 2011.

[37] K. Bhattacharyya, "Dual solutions in unsteady stagnation-point flow over a shrinking sheet," Chinese Physics Letters, vol. 28, no. 8, Article ID 084702, 2011.

[38] S. Mukhopadhyay, K. Bhattacharyya, and G. C. Layek, "Steady boundary layer flow and heat transfer over a porous moving plate in presence of thermal radiation," International Journal of Heat and Mass Transfer, vol. 54, no. 13-14, pp. 2751-2757, 2011.

[39] K. Bhattacharyya, "Boundary layer flow with diffusion and first-order chemical reaction over a porous flat plate subject to suction/injection and with variable wall concentration," Chemical Engineering Research Bulletin, vol. 15, no. 1, pp. 6-11, 2011.

[40] K. Bhattacharyya, "Effects of heat source/sink on MHD flow and heat transfer over a shrinking sheet with mass suction," Chemical Engineering Research Bulletin, vol. 15, no. 1, pp. 12-17, 2011.

[41] K. Bhattacharyya, S. Mukhopadhyay, G. C. Layek, and I. Pop, "Effects of thermal radiation on micropolar fluid flow and heat transfer over a porous shrinking sheet," International Journal of Heat and Mass Transfer, vol. 55, no. 11-12, pp. 2945-2952, 2012. 

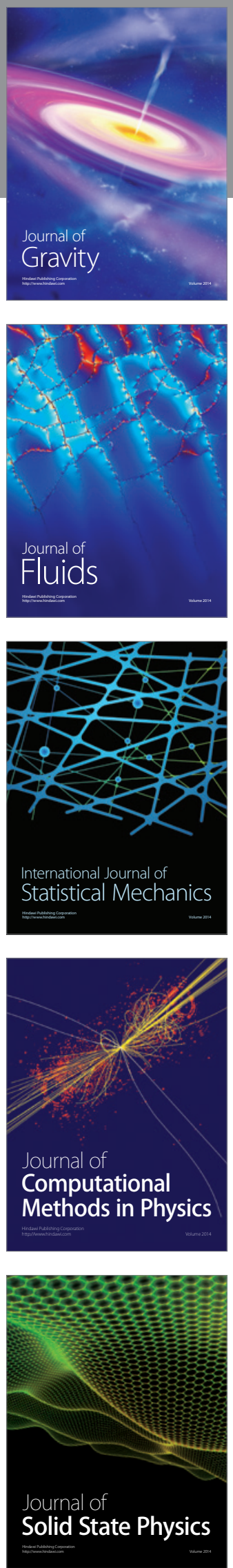

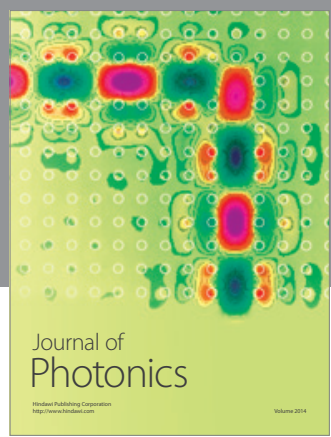

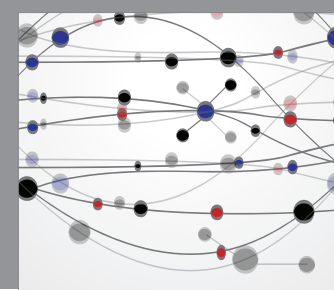

The Scientific World Journal

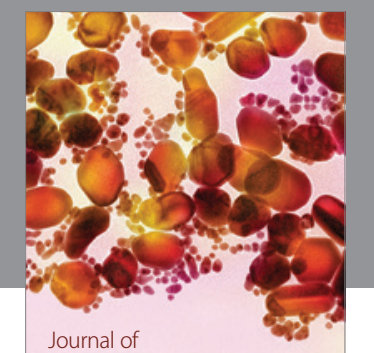

Soft Matter
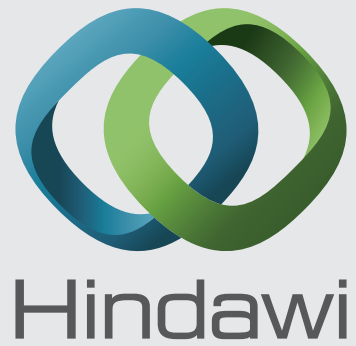

Submit your manuscripts at

http://www.hindawi.com
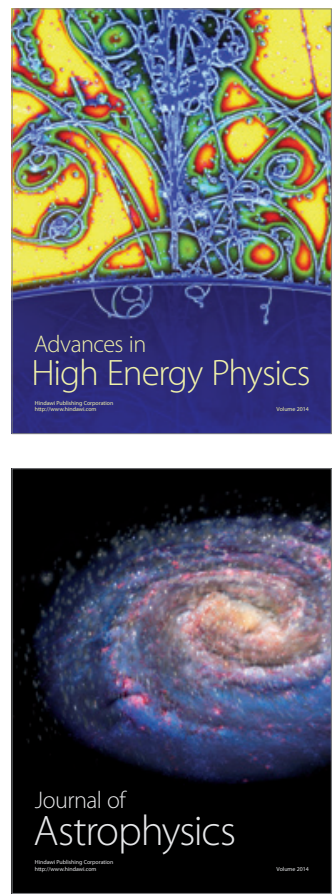
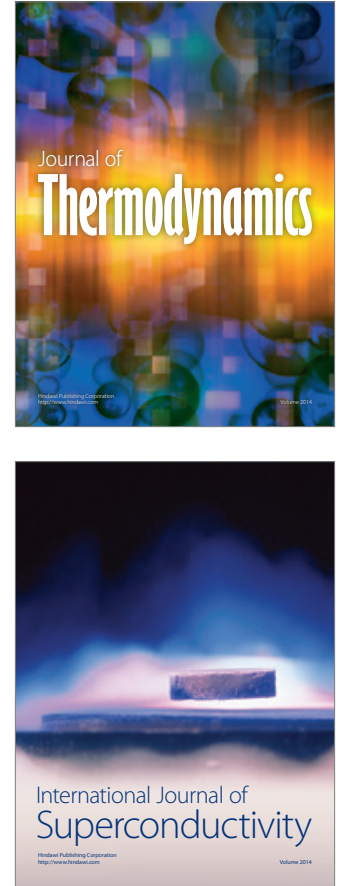
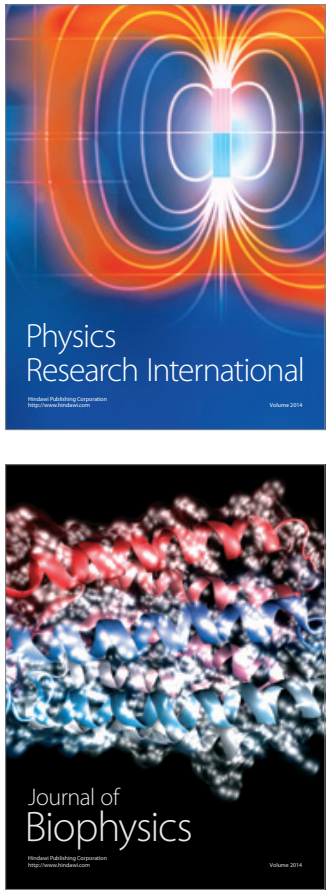
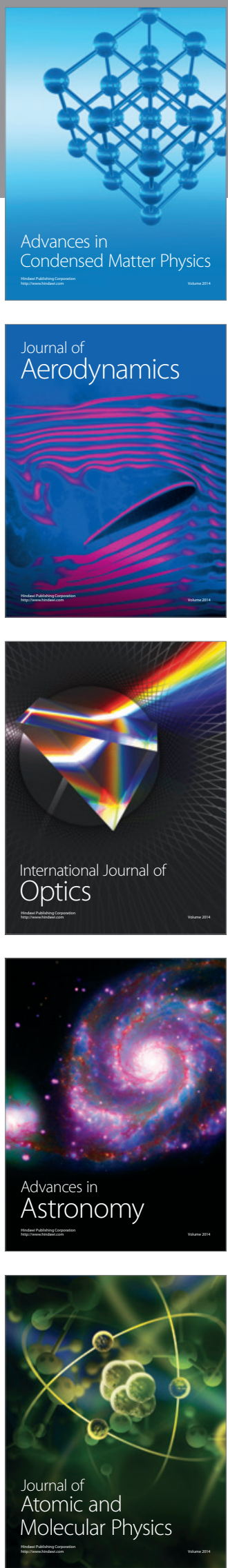